\title{
La Reescritura de Carpentier, Según Roberto González Echevarria*
}

Si la lectura crítica de la narrativa hispanoamericana ha privilegiado a Borges en los años sesenta, el decenio en curso registra una acentuada predilección por Alejo Carpentier. Las recopilaciones y libros publicados, y aún los inéditos, muestran que su obra ha sido complaciente a versiones didácticas, biográficas, contextuales, temáticas, estilisticas, dialécticas y estructuralistas. Más allá de los factores de orden ideológico-metodológico $-\mathrm{y}$ de la necesidad ocasional de renovación de los objetos de estudio académico- el cambio se justifica por el interés en identificar las matrices ficcionales de la nueva novela en su vertiente americanista. Sin embargo, lo que ha podido resistir, por detrás de una aparente flexibilidad, es justamente el modo carpenteriano de invertir en la forma novelesca un sentido de nuestra cultura. Así, dos problemas correlativos de su obra han permanecido insolubles: a) qué elementos ideológicos de la obra de Carpentier se subsuman a la crisis de la cultura latinoamericana y a la modernidad occidental; b) cómo opera en su narrativa la inversión del concepto de Historia de América. Está claro que, si el abordaje del primer problema implica una perspectiva crítica y la del segundo un método analítico, la interrelación de ambos depende de una teoría del texto que permita articular lo ideológico y lo ficcional.

Los cuatro densos capitulos de Alejo Carpentier: The Pilgrim at Home muestran que Roberto González Echevarrǐa ha tratado de conjugar su proyecto crítico con el analítico, para formular que la contradictoria busca carpenteriana de una conciencia americana ha producido un modelo ficcional simbolizante de esa misma busca. La

*Roberto González Echevarria, Alejo Carpentier: The Pilgrim at Home (Ithaca: Cornell University Press, 1977). 
división del corpus en decenios, lejos de ser una comodidad cronológica, resulta de la configuración de etapas que historian la fundación (la fijación) de una escritura. Algunas fechas sirven de marco a ese proceso evolutivo, pero no lineal: 1939, año del retorno de Carpentier a Cuba; 1948, año de su segundo viaje a la selva amazónica; 1962, año de la publicación de El siglo de las luces. Son años simbólicos, de retornos, conversiones y recomienzos, que diseñan la reescritura de Carpentier. Me dedicaré aquí a comentar el modo cómo Roberto González instala el concepto de la reescritura, a partir de la interrelación de los dos proyectos que señalé, sin pretender seguir los fascinantes análisis de cada texto en todas sus implicaciones.

La estrategia analítica general consiste en desmontar primero el edificio de las ideas filosóficas, estéticas y políticas que comparecen en ensayos y artículos de Carpentier, para luego observar su modo de inserción en los textos de ficción de los perỉodos decenales. Estos "cortes" en la diacronia permiten reunir grupos relativamente homogéneos de obras en cuanto al modo de "filtrage" narrativo de ciertos presupuestos ideológicos (término que Roberto González nunca emplea), siempre referidos a la noción de "cultura americana". La constatación de una "relación negativa" entre el ensayo y la ficción lleva a formular el pattern crïtico general: la discrepancia, la contradicción en el centro de la producción carpenteriana, cuya amenazada cohesión se asegura por la "presencia estable o progresivamente expandida" del yo autoral (p. 17). Aún rechazando el entronque mecánico de la vida y la obra, a la manera de la vieja crítica, Roberto González no consigue (no quiere) desentenderse de la cuestión autoral. Para no perder el rico filón interpretativo de la mencionada contradicción y, tal vez, la meta de un estudio orgánico, opta por negar la "unidad biográfica" (el "yo origen"), ordenador y coherente, para rescatar la entidad autoral, desde el ángulo del enmascaramiento literario. Esta solución, si bien no elimina el constante riesgo de confundir autor y narrador, logra resultados positivos en los análisis particulares, en cuanto que la conversión de Carpentier en personaje (Los pasos perdidos, El acoso) se abre a la autorreflexividad narracional y a la metaforización del propio texto.

El examen de la "gestación de una obra" pasa por las lecturas e influencias de los años veinte y treinta: de Spengler y Ortega, via $R e$ vista de Occidente; del afrocubanismo, estimulado por los estudios económicos y sociológicos de Ramiro Guerra y Fernando Ortiz; del surrealismo posteriormente renegado. De este polivalente repertorio que califica de postromántico, Roberto González extrae los ideolo- 
gemas que, ligeramente transformados, presidirán la trayectoria entera de Carpentier: el relativismo del concepto de Historia Universal (concepción cỉclica de las culturas y pérdida de la centralidad europea); valoración de lo primitivo opuesto al racionalismo decadente europeo; concepción casi-religiosa de la actividad poética. Si bien reconoce el autor que la hipóstasis surrealista de lo poético significó un punto de comunión entre Carpentier y el vanguardismo, al omitir la importancia del concepto bretoniano de lo "merveilleux", del Segundo Manifiesto, perderá sólidos argumentos para explicar las bases de la metáfora de lo "real maravilloso americano", núcleo del prólogo a El reino de este mundo. Sin embargo, el interés teórico de Roberto González se concentra en el modelo spengleriano manejado por Carpentier: caída y resurrección, apocalipsis y recomienzo -estructurado sobre la oposición entre reflexividad y fe y que, a diferencia del universalismo vanguardista, aseguraba la especificidad de América Latina como cultura (p. 59).

Si comparamos ese modelo con la simbología del esquema cronológico de la reescritura, se puede fácilmente inferir que hay una analogía entre el modelo spengleriano y la trayectoria literaria de Carpentier: el constante re-comenzar, re-buscar, re-escribir. Una especie de esencial "sisifidad" -como la del protagonista de Los pasoscaracteriza esa busca, siempre renovada por la conciencia de la necesidad de la tarea.

Según Roberto González, las tentativas de los años veinte y treinta de actualizar en la ficción el modelo spengleriano - de relacionar Historia y narrativa- se malogran debido a una suerte de "teología de la narrativa", impuesta desde una visión ajena al universo negro. Aunque Carpentier tratase de romper con el paradigma novelesco mundonovista, yuxtaponiendo escenas y cuadros descriptivos exentos de conexión causal, al modo del "ritmo vital" del collage, es a nivel narracional donde se denuncia la imposibilidad de asimilar la cultura negra: tono culto y retórico, de intención política evidente; explicitación de la voz generadora del texto, portadora de la óptica racional del blanco. A partir de esos fracasos, la tarea de Carpentier se concentrará, dice Roberto González, en resolver la crisis de la novela por la aplicación de una "metáfora de orden", más allá del desarrollo lineal de la trama. El orden unificador se hallará en una "red de relaciones simbólicas, fuera de la acción", en un sistema atemporal, afín al modelo spengleriano de cultura, basado en la expresión simbólica de la naturaleza. (pp. 93-94).

Es en el análisis de El reino donde Roberto González explicita 
mejor esa teoria del texto que atraviesa su ensayo. Un excelente panorama de la América Latina de los años cuarenta -sólo objetable por la omisión del Brasil (como, por lo demás, en la América "Latina" de todo el libro) - sirve para ubicar el prólogo a El reino en el contexto preciso de la investigación sobre el "ser americano" y discutir la supuesta vinculación de "lo real maravilloso americano" y el "realismo mágico".

La primera propuesta del autor para distinguirlos consiste en identificar el realismo mágico con la narrativa fantástica, o sea, la que no depende de las leyes naturales o fǘsicas, ni de la concepción de lo real en la cultura burguesa occidental (p. 109). Se puede objetar esta definición si recordamos, por un lado, que el excesivo alegorismo en las ficciones de Carpentier lo excluyen de la modalidad fantástica; por otro, el núcleo funcional de ésta -tanto en las acepciones de Vax, Lovecraft, Caillois, como en las de Todorov o Bellemin Noëldepende de las leyes naturales, puesto que sólo asegurándolas puede el narrador introducir lo fantasmagórico (el ágora es el espacio de las naturales). Le segunda y más consistente propuesta consiste en distinguir dos versiones del realismo mágico: la fenomenológica, derivada de la teoría postexpresionista de Franz Roh, en que lo mágico depende del modo de percepción de un objeto real; la ontológica, derivada del surrealismo y de las investigaciones etnológicas que valorizaron las culturas primitivas, provocando el descrédito del logocentrismo europeo. Esta versión se prestaría mejor a los objetivos del escritor latinoamericano, ávido de atribuir una esencia mágica a su América. Observa Roberto González, con acierto, que el efecto de tal irracionalismo descentralizante en la narrativa ha sido suprimir la causalidad determinista en la trama (p. 118). En "El arte narrativo y la magia" reconoce el autor la posible teorización de ese proceso mágico que rija la ficción, según Borges, como "un juego preciso de vigilancias, ecos y afinidades". Roberto González se da cuenta, está claro, que Borges no niega la causalidad del relato, pero no señala la diferencia fundamental entre sus postulaciones y la versión ontológica del realismo mágico. Mientras en ésta lo real es predicado con rasgos sobrenaturales, la teoría de Borges es esencialmente formalista $-\mathrm{y}$ por cierto, sorprendentemente coincidente con el concepto de función de Propp (1928), que ha inseminado la semiología de la narrativa de los años sesenta-: lo mágico depende de la articulación económica de las funciones narrativas, cuyas conexiones causales, imprescindibles a la inteligibilidad del relato, deben ocultarse en pro de una instancia semántica superior. Lo que es patente en la oposición 
borgiana entre "el asiático desorden del mundo real" y "la frenética y precisa causalidad" de la ficción, es que la "magia narrativa", antinatural y harmónica, es una operación artificial, que desplaza la obviedad del causalismo realista y crea una supracausalidad en la red de motivaciones, vale decir, en el paradigma textual.

Pero Carpentier, al contrario de Borges, se ha aficionado (teóricamente) a la vertiente ontológica del realismo mágico, y si su famoso prólogo carece de rigor conceptual, en la praxis narrativa intentará erigir a América como (otro) paradigma histórico. Roberto González demuestra, en el paciente análisis de El reino, cómo el propósito de una teleología narrativa se efectúa a través de la estrategia relacional entre la escritura y el cosmos: el ritmo alternante de los eventos históricos y los elementos astrológicos, proféticos, conjuros y rituales, que engendran una estructuración no causal del enunciado; una deliberada combinación de relato y magia, una "complicidad entre Historia y Naturaleza" que atestiguan la busca carpenteriana de ser "autóctone" al escribir. (cf. pp. 137-148).

Ese logos autoral, fuertemente marcado en la producción de los años cuarenta, será cuestionado en Los pasos y negado en El acoso. Momentos de conversión, de la "división de las aguas", estas novelas significan, en el proceso esbozado por Roberto González, la alteración consciente del proyecto literario a nivel temático (substitución de la historia continental por la autobiografía problematizada) y a nivel discursivo (fragmentación y descentramiento de la voz narrativa, autorreflexividad y metaforización). Caracterizando aš̃ una especie de "conciencia de la reescritura", Roberto González recorre sistemáticamente los meandros de la incorporación de textos en Los pasos: el existencialismo sartreano, el diario de los viajes de $1947 \mathrm{y}$ 48 a la selva (el libro de la gran sabana), los mitos de Ulises, Jasón y Prometeo (curiosamente el autor no menciona el de Sísifo), las doctrinas románticas, via Schiller, Shelley, Beethoven y los Travels in British Guiana 1840-1844, de los hermanos Schomburgk. En este conjunto hay que lamentar la omisión de las Meditaciones sudamericanas, de Keyserling y de una "fuente secreta", científica: la portentosa obra en cinco volúmenes del etnólogo alemán Theodor KochGrünberg, Vom Roroima zum Orinoco, de 1923, donde Carpentier adquirió los conocimientos sobre las culturas indígenas americanas que aparecen en la novela.

Como Los pasos, El acoso trae la marca de un simbolismo autorreflexivo, sostenido igualmente por el dialogismo textual, pero ahora abierto a la emblematización de la escritura. En el más ceñido análisis 
de texto de su libro, Roberto González establece la relación intrínseca entre los segmentos discursivos alegóricos, calcados en la arquitectura gótica, via Worringer, y la narración autorreferencial, apoyada en los motivos de la "lectura". El producto de esa relación, el arquitexto, configura para el autor el emblema de la novela: el espacio de la escritura que amenaza petrificarse, dentro de la misma dialéctica del deseo y el miedo que atrapa al personaje acosado.

Una similar, pero más acabada materialidad emblemática caracteriza la más reciente etapa de la reconversión carpenteriana. El siglo de las luces, El recurso del método y Concierto barroco acogen, para Roberto González, el nuevo intento de capturar el sentido de la Historia de América- reconociéndolo en su "segundo nacimiento", el siglo XVIII, el momento del definitivo asentamiento de la modernidad - . La fundación del estatuto escritural latinoamericano es reconocida en la práctica del "tercer estilo", la parodia y el humor, como modos de negar el centro, los orïgenes y afirmar la "imposible harmonia" de nuestra cultura.

The Pilgrim at Home permanecerá, sin duda, como una decisiva contribución a los estudios carpenterianos. Menos por la útil visión de conjunto de la producción de Carpentier, que por la ejemplar integración de los proyectos crítico y analítico del autor en torno a una teoría del texto. Roberto González supera las deficiencias y los clisés del substancialismo horizontal, que demoraba cierta crítica de Carpentier, para ordenar un sistema vertical, no reduccionista, de una trayectoria literaria e ideológica. Junto a esas virtudes, comparecen algunas debilidades que merecen mencionarse.

La principal, me parece, es la ausencia de fundamentación teórica sobre términos empleados en los análisis. Al evitar las definiciones previas, el autor logró aligerar el ritmo de su discurso crítico, pero también dió lugar a lagunas teóricas y vacilaciones terminológicas. Entre éstas, la más flagrante es el tratamiento indiscriminado de los dos aspectos de la narración, el punto de vista (o perspectiva, o visión) y la "voz" narrativa. Asî́, el estudio de ¡Ecué-Yamba-O! registra la primera acepción (relación del narrador con el enunciado); el de Los pasos, principalmente con la segunda (relación del narrador con el discurso); el de El siglo mezcla a ambas. La diferencia, muy bien formulada por Genette en Figures III, permitiria sistematizar mejor la evolución carpenteriana hacia la autorreflexividad. Otro ejemplo es el empleo de "writing", concepto central y nunca definido en el libro, que corresponde, las más veces, a la "écriture" barthesiana, pero que llega a ser sinónimo de "tiempo representado" 
y "composición" (en el análisis de El reino, pp. 129-147) y "narración" (p. 191). En otros casos, se trata de confudir conceptos emparentados, pero no equivalentes, como: "composition en abîme" (la "mise en abyme" de Gide)- que implica la reproducción total o parcial de la historia en la historia, no de modo alusivo, sino literal (Ricardou, D'Allembach)- se empleada por "autorreferencialidad" ( $p$. 183); y aún, la aplicación del término "parodia" a ejemplos de citas no irrisorias, que son, más bien, intertextuales. (p. 256).

Aunque Roberto González se mueva predominantemente en el ámbito del "New Criticism" (character, point of view, setting, action, self-conscious narrator, authorial voice, etc.), hay momentos de fisura entre la praxis analítica y la teoría. Ejemplo de ello es la definición simplista de novela, conforme a Richardson, como el resultado de una "organic relationship between character and setting" (p. 190), mientras los análisis (sobretodo de $E l$ acoso, Los pasos, El siglo) se filian más bien a nociones más actuales y fecundas como "productividad", "polifonǐa", "dialogismo" (Bakhtine, Kristeva).

Ya habíamos visto que la teoría del texto, deductible de los análisis, era informada por la relación simbólica (motivada, en términos saussurianos) entre la narrativa (elemento simbolizante) y la Historia, colectiva o personal (elemento simbolizado). La demostración de tal simbolismo, que se intensifica hasta la alegorìa y el emblema, requiere, evidentemente, el desplazamiento del relato para el discurso. Vale decir, para los temos, los motivos, el punto de vista, la "voz" - que son unidades fuera de la acción. Esa diferencia tiene importantes consecuencias para evaluar el resultado final de la tesis de Roberto González sobre el modelo ficcional carpenteriano. La escasa atención a la materialidad narrativa lleva el autor a construir dicho modelo sobre los paradigmas y a extraer la estricta significación analógica, propia de la simbólica. La cuestión, es, pues, saber si, más allá de la analogía de las substancias, formulada rigurosamente desde el centro paradigmático de los textos, habrìa una homología de formas entre la narrativa y la Historia, desde el centro sintagmático de los relatos.

Esta respuesta debe encontrarse, tal vez, desde otra perspectiva crìtica, la que permitiese relacionar la ficción y el ensayo, sin atribuir cualquier valor de verdad o falsedad a los postulados "teóricos" de Carpentier. Roberto González no comete la ingenuidad de poner los relatos de Carpentier contra una pantalla axiológica, pero insiste en señalar la falta de coherencia de su ensayistica y la imposibilidad de todo nexo entre la literatura y su referente (p. 129). Este "referen- 
te", siempre que no sea entendido como lo "real", resulta ser la misma ideologïa (falsa conciencia) de la cultura americana de los ensayos de Carpentier y los de tantos otros ideólogos de la "identidad latinoamericana".

No cabe discutir aquï el modo de conversión de esa ideología a lo poético. Pero quisiera señalar que en el prefacio autocrítico de su libro, -la "Post Carpenterian reflection"-- Roberto González admite finalmente que el tema de nuestra identidad es una convención, cuya función es retórica y, por tanto, carece de validez referencial (p. 20). Ese desenlace, que reinterpreta la tesis de la contradicción, abre nuevas posibilidades para releer a Carpentier.

Universidad de São Paulo

IRLEMAR CHIAMPI CORTEZ 